\title{
The 3P Business Creation Competition
}

\author{
Jedes Jahr schreibt eine Studentenorganisation der Universität Cambridge einen \\ Wettbewerb für Geschäftsideen aus, die soziale Aspekte oder Umweltbelange \\ betonen. Die Gewinner erhalten einen Geldpreis sowie Zugang zu Gründernetz- \\ werken und Kontakt mit Investoren. Der Erfolg: Die Zahl der Teilnehmer steigt, \\ die Umsätze der gegründeten Gewinnerfirmen auch.
}

Von Nicola J. Dee 3P, short for People, Planet, Productivity, is a business creation competition for socially and environmentally explicit businesses which are either for-profit or non-profit. The competition was launched by Cambridge University Entrepreneurs (CU Entrepreneurs) in 2003. Its aim was to fill a perceived need in the student population for opportunities in social and environmental entrepreneurship. CU Entrepreneurs is a student run society which runs the $£ 50 \mathrm{~K}$ and $3 \mathrm{P}$ business creation competitions and the $£ 1 \mathrm{~K}$ business idea competition. Since the launch of the society in 1999 they have distributed over 250,000 pound sterling in prizes and have helped over twenty-three new companies get started.

\section{Context Setting}

The Cambridge high-technology cluster has earned the region the nick-name of 'Silicon Fen' after its more famous cousin 'Silicon Valley'. By 2000, around 1,160 technology based companies, employing 38,000 people were based in Cambridgeshire positioning the region as one of Europe's most active high-technology clusters. Science parks and incubators, networking organisations, investors' groups and funds, professional service providers, public agencies, and technology providers have developed to support entrepreneurs and their firms.

In response to the Cambridge phenomena and support from the U.K. government the University mobilised resources to enhance business creation activities from the 1980s onwards. Whilst these activities have gone through a number of iterations, two offices of the university have been instrumental in their support for CU Entrepreneurs - The Centre for Entrepreneurial Learning (CfEL) delivers a range of educational activities on the practice of entrepreneurship, to inspire and build skills.

- Cambridge Enterprise exists to help University of Cambridge inventors, innovators and entrepreneurs make their ideas and concepts more commercially successful.

\section{How the 3P Competition works}

There are a number of essential elements which combine and make the 3P Competition work. These are delivered through close collaboration and organisation between CU Entrepreneurs, Cambridge Enterprise and CfEL.

The time-table of the business creation competition works alongside the academic year (Figure 1). Executive summaries are of no more than 1500 words, and full business plans must be no more than forty pages in total excluding team résumés. Each team entering the competition must have at least one full-time Cambridge University student although competitors are encouraged to seek the involvement of faculty members, alumni, postdocs, researchers and other staff and there is no restriction on team size. CU Entrepreneurs used to facilitate all teaching prior to the formation of the Cambridge Entrepreneurship Centre but does this now with CfEL. One of the main teaching pro- grammes is called Enterprise Tuesday and is open to all members of the University. An essential element of this programme is bringing in experienced entrepreneurs and business people to teach and inspire. Finalists for the competition also attend a customised intensive training weekend and have access to free surgeries by service providers which are organised by Cambridge Enterprise. These taught skills and free advice are complemented by the addition of experience which is enabled through pairing up finalists with mentors who are practised in entrepreneurship. The mentors are organised by Cambridge Enterprise.

Much of the teaching and training available to business competition entrants is relevant to both $3 \mathrm{P}$ and $£ 50 \mathrm{k}$, though speakers should be apprised of the audience to avoid alienation of either group. 3P entrants are given additional sessions on how to report social and environmental aspects of their business, alternative sources of finance, and the choice of legal structures on which to form their organisation.

CfEL market entrepreneurship in general with competition specific marketing undertaken by $\mathrm{CU}$ Entrepreneurs. One very successful strategy has been to work with course organisers who are able to incorporate the development of a business idea within their course.

Essential to making the transition between business idea and business creation is the formation of a good team, drawing on help and experience from others and building confidence. Networking is indispensable in achieving all of these and for which we provide a variety of opportunities.

Success is celebrated throughout the year especially at the black-tie Qualifiers Dinner, the Winner's Drinks Evening and Gala Networking Event. These events raise the profile of our winners, build excitement in entrants and the wider business community whilst offering thanks to our supporters, and have become a key-date in the diaries of many local investors.

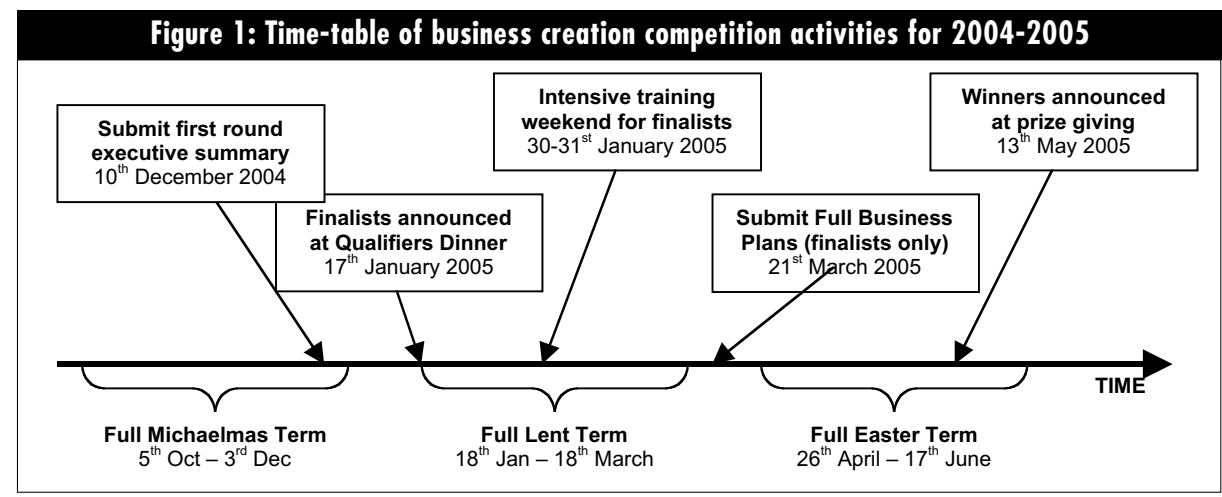




\section{- Resources for the 3P Competition}

CU Entrepreneurs is run by student volunteers and therefore incurs few administrative costs, its partners and individuals from the business community also volunteer their time. Every year CU Entrepreneurs raises enough sponsorship to cover prize money $(£ 80,000)$ and money for events i.e. up to $£ 110,000$ total. Unfortunately it has become increasingly difficult to raise this money; therefore prizes are being diversified into services and cash. Part of this year's prize, for example is incubation space at the Science Park. We approach service providers such as law firms; investors such as venture capitalists; and other organisations to sponsor us.

There were various concerns regarding how to formulate the judging criteria. We had heard stories from other social venture competitions which had experienced conflict among judges as a result of poor judging criteria. We designed the criteria in the same format as the $\$ 50 \mathrm{~K}$ competition but tailored it towards 3P and have received positive feedback of it from judges. We carefully chose judges who were experienced in 3P activities, not only for their expertise but also so they could cope with any problems incurred during the judging process.

\section{> Conclusion}

The 3P competition is a contrast to the high-technology high-growth culture of Cambridge. Whilst these businesses are not excluded from 3P, they must be socially or environmentally explicit. It has at times been challenging to explain the concept of 3P to the existing entrepreneurial support infras- tructure which judges success by the ability of a business to make money. In addition much of our partners funding is conditional on the support of $£ 50 \mathrm{k}$ type businesses and they remain slow to respond to the extra needs of $3 \mathrm{P}$. However, new activities are mobilising which cater for $3 \mathrm{P}$ businesses and this restricted metric of success is shifting. The competition is judged by the number of entrants and the quality of winners. Last year we nearly equalled the number of entrants to the es-

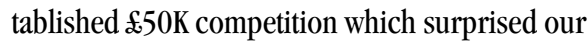
sceptics. Winners in 2004 included Aidworld and DiagnovIS; both are thriving.

Running the competition through a student run organisation such as CU Entrepreneurs has exceptional advantages for communication with students and builds momentum and enthusiasm throughout the year's programme. However, since the organisation is run by volunteers there is a high-turnover rate which can hinder continuity of organisational activities. On a positive note, many CU Entrepreneurs volunteers later become competition entrants.

Although the partnership between CU Entrepreneurs, CfEL and Cambridge Enterprise is essential to the professional delivery of supporting activities to the business creation competitions, it is sometimes difficult to manage. It is easy for partners to try and avoid organisational responsibility whilst capitalising on any positive press. The three organisations can easily be confused by outsiders, and all rely on outside funding mainly in the form of sponsorship, therefore diluting available finance. This partnership is under constant re-assessment in order to delineate activities and reduce conflicts.
The 3P competition is not only providing a startup opportunity for socially and environmentally explicit businesses which are either for-profit or non-profit, but also brings an increased awareness of sustainability to the $£ 50 \mathrm{~K}$ competition and the Cambridgeshire entrepreneurship support infrastructure. Already we are seeing overlaps between the $\mathfrak{f} 50 \mathrm{~K}$ and $3 \mathrm{P}$ business creation competitions and we hope these continue in the future so that these competitions can one day be merged. Contemporary businesses are increasingly judged in the broader framework of sustainability as the anthropogenic effects of environmental and social neglect become more prevalent. 3P is timely and successful in building awareness of sustainable development through the creation of sustainable businesses, as reflected in the increasing interest this competition has attracted from others wishing to establish similar competitions.

\section{Die Autorin}

Nicola J. Dee ist Doktorandin an der Universität Cambridge und Mitglied von CU Enterpreneurs. Kontakt: CU Entrepreneurs, Institute for Manufacturing, Mill Lane, Cambridge University CB2 IRX, U.K. E-Mail: nd248@cam.ac.uk, Website.www.cue.org.uk 
(c) 20I0 Authors; licensee IÖW and oekom verlag. This is an article distributed under the terms of the Creative Commons Attribution Non-Commercial No Derivates License (http://creativecommons.org/licenses/by-nc-nd/3.o/), which permits unrestricted use, distribution, and reproduction in any medium, provided the original work is properly cited. 